\title{
Violência, estética e educação: o caso do jovem Törless
}

\author{
Violence, aesthetics and education: the case of young Törless
}

\section{Violencia, estética y educación: el caso del joven Törless}

\author{
Nadja Hermann ${ }^{2}$ \\ Pesquisadora no Conselho Nacional de Desenuolvimento Científico e Tecnológico (CNPq)
}

Essa ilusão, esse pequeno truque em favor da evolução espiritual dos jovens, era o que faltava no internato. Tudo lhe parecia palpável, e ainda assim impossível de jamais se resolver em pensamentos e palavras. Entre os fatos externos e o seu eu, sim, entre suas próprias emoções e o seu eu mais remoto, que ansiava por entendê-las, haveria sempre uma linha divisória que, como um horizonte, recuava ante o seu anseio. Quanto mais minuciosamente tentasse revestir as emoções com idéias, quanto mais as conhecia, mais estranhas e incompreensíveis lhes pareciam, de modo que já nem era como se recuassem diante dele, mas ele próprio se afastava, sem contudo livrar-se da impressão de que se aproximava delas. (Robert Musil, O jovem Törless).

Resumo: $\bigcirc$ artigo discute a possibilidade da estética iluminar a ética na educação, interpretando a violência no processo formativo, a partir do Bildungsroman O Jovem Törless (1906), de Robert Musil. A consideração do sensível (aisthesis) para mobilizar os afetos e as emoções é uma estratégia que articula a complementaridade entre o saber filosófico (ética) e aquele que provém da literatura e das artes em geral (estética). O Jovem Törless aborda a violência no processo educativo, provocando a emoção que vincula o ético no estético e, assim, expõe como se preparam as mentalidades autoritárias. Por fim, o texto conclui que a criação poética de Musil expõe o avesso da educação, uma vez que a ordem da instituição educacional é subvertida pela desordem violenta que, trabalhada no processo interno dos sentimentos, provoca o próprio da estética: "emoção extrema".

Palavras-chave: Violência. Educação. Estética. Ética. Musil.

Este texto integra a pesquisa Ética e educação: a questão do outro III, financiada pelo CNPq.

2 Doutora em Educação pela Universidade Federal do Rio Grande do Sul, com estudos complementares (Doutorado-sanduíche) na Universidade de Heidelberg; Mestre em Educação pela Pontifícia Universidade Católica do Rio Grande do Sul. 
Abstract: The article discusses the possibility of aesthetics to illuminate ethic in education, interpreting violence in the formative process, from the Bildungsroman The Young Törless (1906), by Robert Musil. The consideration of the sensitive (aisthesis) to mobilize affections and emotions is a strategy that articulates the complementarity between philosophical (ethical) knowledge and that which comes from literature and the arts in general (aesthetics). Young Törless approaches violence in the educational process, provoking the emotion that links the ethical to the aesthetic and thus exposes how the authoritarian mentalities are prepared. Finally, the text concludes that the poetic creation of Musil exposes the reverse of education, since the order of the educational institution is subverted by the violent disorder that, worked in the internal process of the feelings, provokes the proper one of the aesthetic: "extreme emotion".

Keywords: Violence. Education. Aesthetics. Ethic. Musil.

Resumen: El artículo discute la posibilidad de la estética iluminar la ética en la educación, interpretando la violencia en el proceso formativo, a partir del Bildungsroman El Joven Törless (1906), de Robert Musil. La consideración del sensible (aisthesis) para movilizar los afectos y las emociones es una estrategia que articula la complementariedad entre el saber filosófico (ética) y aquel que proviene de la literatura y de las artes en general (estética). El joven Törless aborda la violencia en el proceso educativo, provocando la emoción que vincula lo ético en lo estético y, así, expone cómo se preparan las mentalidades autoritarias. Por último, el texto concluye que la creación poética de Musil expone el revés de la educación, una vez que el orden de la institución educativa es subvertida por el desorden violento que, trabajada en el proceso interno de los sentimientos, provoca lo propio de la estética: "emoción extrema".

Palabras clave: Violencia. Educación. Estética. Ética. Musil.

\section{INTRODUÇÃO}

O tema "violência, estética e educação" é bastante amplo e permite diversos modos de abordagem. Pretendo circunscrevê-lo pela possibilidade da estética iluminar a ética na educação e, particularmente, interpretar a violência 
enquanto uma transgressão ética no processo formativo. Há muitas razões para justificar essa possibilidade. Eagleton (1993, p. 8) destaca que a proeminência da estética na modernidade se relaciona com certa indeterminação conceitual que remete para temas como liberdade, autodeterminação, particularidade, autonomia, entre outros que se relacionam com o novo formato de subjetividade em curso. Ou seja, a estética amplia experiências de subjetividade, podendo trazer à tona aquilo que é indeterminável conceitualmente. Assim, antecipa certas verdades sobre nós e o mundo, como já havia observado Freud ${ }^{3}$ ao afirmar que os poetas descobriram o inconsciente antes dele. A dificuldade com aqueles elementos que escapam ao conhecimento racional e a valorização do sensível levam a estética a ser incluída no âmbito de uma racionalidade alargada com condições de enfrentar as grandes ilusões e desilusões da modernidade. A esse respeito, Lyotard (1996, p. 214) chamou a atenção que, quando os ideais faltam, a estética os representa, pois o sensível "arromba uma inexistência inerte. [...] Um som, um odor, uma cor tiram do contínuo neutro, do vácuo, a pulsação de um sentimento", trazendo certo desconcerto ao pensamento, que o provoca. Esse amplo contexto abriu espaço para investigar a mútua e fecunda participação do estético no ético, o sentido que a estética pode assumir para o agir moral, especialmente para a formação humana. Portanto, a estética não será aqui trabalhada como uma teoria da arte, nem como um mero esteticismo, em que a arte teria um valor por si mesmo, numa posição tão autônoma que impediria sua relação com qualquer categoria moral, mas relacionada com o sensível (aisthesis) que mobiliza os afetos. Uma mobilização dessa natureza provoca a revisão de nossas crenças, favorece o conhecimento de como as paixões agem sobre nós e aprimora nossa sensibilidade ética. $\bigcirc$ inesperado efeito produzido por uma forma artística interroga a moralidade vigente, exige novas formas de integração entre o intelecto e as emoções e produz experiências de subjetivação.

Nesse contexto, tampouco pretendo trabalhar a estetização da violência pelo choque que afeta os sentidos, como ocorre nas transmissões ao

\footnotetext{
3 Freud faz essa referência na Conferência XXXIII, que trata da feminilidade, indicando que a criação poética coloca no sensível, ou seja, no plano estético, os elementos que posteriormente serão trabalhados pela ciência.
} 
vivo pela mídia e redes sociais de cenas brutais de decapitação realizadas por terroristas e assassinos com a intenção de intimidar, horrorizar e espalhar o medo. Nesse caso, a estetização alia-se à manipulação emocional e ideológica para agredir a sensibilidade e atua como um choque, muito excitante, mas pouco profundo, sem conseguir trabalhar as emoções.

Escolhi abordar a violência pela criação literária de Robert Musil (1880-1942), na obra O jovem Törless ${ }^{4}$ (Die Verwirrungen des Zöglings Törless), publicada em 1906. Musil é considerado um dos mais importantes autores da literatura contemporânea, que penetrou nas entranhas éticas e estéticas da modernidade tardia, dando um novo impulso a essas duas áreas. Inicialmente pretendo apresentar uma breve contextualização da relação entre estética e ética, para, num segundo momento, situar o modo como a obra $\bigcirc$ jovem Törless, caracterizada como um Bilgunsroman, aborda a violência no processo educativo, provocando a emoção que liga o ético e o estético. Por fim, o texto conclui que a criação poética de Musil mostra a formação pelo seu avesso, ou seja, a ordem da instituição educacional é subvertida pela desordem violenta que, trabalhada no processo interno dos sentimentos, provoca o próprio da estética: "emoção extrema".

\footnotetext{
4 Há muitas interpretações a respeito de $O$ jovem Törless, decorrentes da riqueza dos problemas psicológicos, sociais, políticos, éticos e estéticos que apresenta, como consta na obra de Allen Thihrer, Understanding Robert Musil (2009). Rosenfield (2012b) inventaria as posições mais relevantes sobre o romance, que incluem a interpretação de Howald, a respeito do esteticismo; a interpretação de Mulot, que defende uma visão ética e não apenas o esteticismo; a defesa da atitude emocional passiva de Törless por Frier, entre outras. Rosenfield, por sua vez, faz uma interpretação inovadora no artigo Musil's idea of poetic mastership and responsibility or: Törless as his first attempt to become a serious writer, cujo propósito é "mostrar que o egoísmo passivo do herói, que se baseia em estereótipos filosóficos e literários do impressionismo, é melhor visto como uma recusa ativa para desenvolver outras alternativas e atitudes (artísticas ou científicas) que o narrador aponta como mais desejável do que as escolhas de Törless. A técnica narrativa de Musil esboça discretamente em um horizonte remoto de valores morais e artísticos aquilo que o egoísmo confuso do adolescente não consegue conceber." (ROSENFIELD, 2012b, p. 20-21).
} 


\section{CONSIDERAÇÕES SOBRE ESTÉTICA E A RELAÇÃO COM A ÉTICA ${ }^{5}$}

A estética sempre esteve presente na reflexão filosófica desde o mundo grego, mas como uma disciplina específica foi criada por Baumgarten, no século XVIII, preocupada com o valor cognitivo da percepção sensorial. Sua trajetória foi marcada pelo papel da imaginação e dos sentimentos no conhecimento conceitual. Eagleton (1993, p. 17) observa que é como se a filosofia houvesse subitamente despertado "para o fato de que há um território denso e crescendo para além de seus limites e que ameaça a fugir inteiramente à sua influência. Esse território é nada mais que a totalidade da nossa vida sensível." O pensamento de Schiller (1991, p. 68), ao apostar na educação ético-estética da humanidade em que "o sentimento educado da beleza refina os costumes", constituiu um marco importante de uma sensibilidade filosófica favorável à estética na modernidade. Essa disposição se acentua no século XIX com Schelling, Schopenhauer e Nietzsche ao atribuírem à arte um papel central na condição humana, capaz de expressar e articular aquela realidade mantida presa no conceito e no discurso racional. Nas últimas décadas do século XX, a separação entre os domínios da ética e da estética sofre deslocamentos, as fronteiras tornam-se mais porosas e a própria disciplinarização se fragiliza, abrindo espaço para novos modos de aproximação entre esses âmbitos do saber. ${ }^{6}$ Gadamer (1993, p. 232), para quem a estética ocupa um lugar privilegiado na sua teoria da compreensão, reconhece uma "proximidade enigmática" e uma "tensão frutífera" na relação entre filosofia e poesia, o que não se passou sem "ácidas críticas" no ambiente acadêmico. A ruptura dos limites rígidos entre as disciplinas favoreceu uma relação de complementaridade entre o saber filosófico e aquele que provém da literatura e das artes em

\footnotetext{
Esta parte do texto retoma, com modificações, discussões apresentadas em dois eventos: no "II Simpósio de Estética e Filosofia da Música: Música, Filosofia e Bildung", realizado na Universidade Federal do Rio Grande do Sul, Porto Alegre, de 21 a 23 de setembro de 2016, e no VII Congresso Internacional de Educação, realizado nas Faculdades Palotinas, em Santa Maria, RS, de 10 a 13 de maio de 2017.

6 Ver Hoffmann, Gerhard; e Hornung (Alfred. Ethics and aesthetics: the moral turn of postmodernism. Heidelberg: Universitätverlag C. Winter, 1996), Welsch (1993) e Friicntl (1996)., Wolfgang (Hrsg.). Die Aktualität des Ästhetischen. München: Fink, 1993; FRÜCHTEL, Josef. Äthetische Erfahrung und moralische Urteil. Frankfurt am Main: Suhrkamp, 1996.
} 
geral (NUSSBAUM, 1992; RORTY, 1991), áreas que operam com o sensível (aisthesis), que transcendem as fronteiras meramente racionais, promovendo experiências de subjetividade que não apenas desafiam o modo de pensar a ética como trazem elementos que ampliam a percepção da conduta humana, refinam a capacidade de julgar e nos aproximam de dilemas e particularidades das questões morais. Assim, a ética pode se valer das formas simbólicas e das metáforas para além do argumento racional estrito (VIEJA, 2003).

Além da fragilização das fronteiras entre as áreas do saber, nossa experiência moral e as discussões contemporâneas (WELSCH, 1994, 1995, 1996; RORTY, 1991; FOUCAULT, 1990; NUSSBAUM, 1992) apontam que justificações intelectualistas de princípios e uma ética incorpórea não são suficientes para compreender o agir e que podemos iluminar questões éticas pela expressividade estética, pelas emoções e sentimentos. Nussbaum (1992, 2003) destacou o papel das emoções na deliberação moral, defendendo uma interpretação da ética em que aspectos emocionais e intelectuais se encontram imbricados e que especialmente a literatura (seja na visão dos trágicos gregos seja na visão da literatura contemporânea) pode mostrar exemplos e casos particulares que auxiliam nosso autoconhecimento e, consequentemente, nossa capacidade de decidir moralmente. Portanto, a mera oposição entre conhecimento filosófico e conhecimento proveniente das artes perde sentido, em favor de uma ideia de complementaridade das formas de conhecimento científico, filosófico e artístico. Como a filosofia elabora argumentos em que "elimina a densidade do particular" dado seu caráter abstrato, a literatura pode enriquecer as situações pelos relatos que têm a função de exemplificar, dar voz às recordações, refazer a textura e o colorido das formas de vida (VIEJA, 2003, p. 26). É justamente esse aspecto que incide sobre o processo formativo, pois o desenvolvimento de uma sensibilidade aguçada diante das circunstâncias e das emoções que envolvem as questões éticas pode ser mais efetivo por sua força mobilizadora do que o mero acesso cognitivo a princípios e normas.

Nessa perspectiva, vinculo-me a uma relação de entrelaçamento entre ética e estética como se encontra em Nussbaum, Welsch, Rorty, Adorno, Gadamer, entre outros, em que a ética não é substituída pela estética, mas pode auxiliar a tornar mais esclarecidos tanto os fundamentos éticos quanto 
o agir moral. No romance $\bigcirc$ jovem Törless, a poética de Musil mostra pela emoção como o ético incide no estético, conforme será exposto na sequência.

\section{O JOUEM TÖRLESS: CONSIDERAÇÕES SOBRE O ESTÉTICO E O ÉTICO EM MUSIL}

A força expressiva da obra de Musil é fruto de uma inteligência que, como observa Steiner, "tem algo de mistério" e "é obviamente formidável em sua capacidade de organizar, de afastar-se do foco comum, para recriar nossa leitura do mundo." (STEINER, 1995, p. 1). Para Musil, o nexo entre o ético e o estético se estabelece porque o racional está entrelaçado com a dimensão poética da narrativa literária, sendo capaz de trabalhar valores existenciais. Ele venceu a tentação de fazer ensaio filosófico, empenhando-se em dar à ficção a concretude do local, e essa tensão entre o sistemático e o poético é que confere à sua obra um poder inquietante (STEINER, 1995).

No Caderno 11 dos Diários, Musil (2009, p. 237) se anuncia como "moralmente sensível", numa oposição ao esteticismo ${ }^{7}$ decadente de finde-siecle, que ele chamou "produtos de estufa [...] Sensações construídas, sensações de papel." Musil (2009, p. 239) destaca a importância de uma educação estética na tradição de Schiller, Goethe, Nietzsche, que promoveria o eu ético-estético. Isso é associado a uma autocultura que produz uma vida mais sã, mais autêntica, ou seja, "significa que todas nossas possibilidades vitais são liberadas ao mesmo tempo e crescem; significa, pois, uma liberação e um crescimento que, ao mesmo tempo, potencia a plenitude do pensar, do sentir e do querer." (MUSIL, 2009, p. 241, grifo do autor).

\footnotetext{
7 esteticismo é uma corrente de pensamento do século XIX surgida na Europa (França e Inglaterra, sobretudo) que valoriza beleza, a arte pela arte, em oposição a qualquer instrumentalização da mesma, em especial em relação às questões ético-morais. Reivindica a autonomia da arte diante de qualquer critério exterior a si mesma. A estética passa a ser quase um refúgio da existência. Numa posição contrária ao naturalismo, há uma defesa da produção do artifício, em que o homem corrige a natureza e faz suas próprias leis.
} 
Creio que as vinculações da violência com a educação podem ser compreendidas pela capacidade do autor em provocar a emoção que justamente faz a ligação entre o ético e o estético. Estética para Musil não é uma pura sensação, mas aquilo que resulta do não racional (não racionoide), que se vincula ao imaginativo. Nesse contexto, deve-se também recorrer à distinção que faz entre o moralista e o ético: "O moralista impõe uma ordem lógica [...], não agrega nenhum valor aos valores, só um sistema. Fundamentos, princípios... não ocupam mais que posições relativas no sistema. [...] A maior parte dos filósofos pertence a esse tipo." (MUSIL, 2009, p. 163). Ao passo que o ético é próximo da atividade do poeta, sua contribuição não ocorre por princípios lógicos e racionais, mas pelo material, pelas experiências éticas. É nesse sentido que o ético se relaciona com a imaginação. Musil "não quer dizer que na arte sejam proclamados conteúdos morais, mas visa à emoção extrema que ela pode provocar e que não pode ser simplesmente identificada, mas tem algo a ver com a vertigem." (BOHRER, 2001, p. 12).

É nessas experiências éticas de alto potencial para mobilizar o afetivo e o intelectual que quero mostrar a contribuição de Musil sobre a violência de uma experiência formativa. Fatos aparentemente corriqueiros na ordem normal de uma escola mostram-se de repente pervertidos, estabelecendo uma desordem violenta, difícil de nos situar. O jovem Törless (Die Verwirrungen des Zöglings Törless), publicado em 1906, um dos primeiros romances de Robert Musil, que numa tradução literal seria "As confusões do aluno Törless", tem uma construção poética que entrelaça a percepção sensível com o rigor do pensamento na busca de uma dimensão ética. É considerado um Bildungsroman (romance de formação), tendo, contudo, uma construção bastante distinta dos clássicos desse gênero. O Bildungsroman é uma forma literária que tem origem no final do século XVIII, um fenômeno tipicamente alemão que narra o amadurecimento interior pelo processo educativo, sob condições sociais, históricas e culturais concretas. $\bigcirc$ centro do romance é a própria Bildung (formação), base da sociedade burguesa que passou a ser, nas palavras de Mass (2000, p. 15), "a ferramenta para a transição de uma cultura do mérito herdado para a cultura do mérito pessoal adquirido." 
romance de Musil não apresenta nenhuma formação idealizada como foi o clássico Os anos de aprendizado de Wilhelm Meister, de Goethe, que apresenta a trajetória do protagonista na busca pelo aperfeiçoamento de suas capacidades em prol de um bem comum. Os conflitos e as lutas internas fazem parte de uma formação plena e harmônica, um formar-se a si mesmo, de acordo com as ideias de autonomia e de totalidade do Iluminismo. romance discute as possibilidades e os limites de seguir o caminho em busca da sabedoria da vida, e também a interação entre o indivíduo e a sociedade. Ou seja, é um mundo vivido subjetivamente.

Musil, ao contrário, afasta-se do "foco comum, para recriar nossa leitura do mundo", como lembra Steiner (1995). O jovem Törless se insere no contexto de escolas militares na Alemanha, como são também Debaixo de rodas (Unterm Rad), de Hermann Hesse, e Jakob von Gunten, de Robert Walser. Rompe com a ideia de formação harmônica e plena, para dar lugar à narrativa de uma vivência num internato, que torna visível a crueldade e os mecanismos de perversão, as cruas fantasias sexuais, em que os mais fortes espezinham os mais frágeis, gerando toda ordem de perturbação do espírito. A vontade de poder presente no comportamento dos alunos é uma antecipação das ditaduras e do nazismo, estabelecendo uma ligação entre a disposição mental e as condições para o estabelecimento de regimes ditatoriais. São traços de comportamentos e mentalidade de personagens que preparam o ambiente social da barbárie.

Como talvez nem todos tenham lido o romance, convém relembrar alguns elementos de seu enredo. Törless vai voluntariamente para um internato militar, considerado um lugar "para proteger a juventude das influências corruptoras de uma grande cidade" (MUSIL, 2003, p. 8), embora ocorra o oposto; ou seja, é o ambiente escolar que corrompe os alunos. Lá chegando, quando se fecha o portão do internato - num trocadilho com o nome do protagonista Törless, que significa literalmente sem porta - ele começa a sentir saudades do ambiente familiar. Faz amizade com um príncipe, quase um idílio que o faz se sentir bem; contudo, a amizade é rompida por suas "zombarias racionalistas" a respeito da religiosidade do colega. 
Desde o início fica claro que Törless sentia um "imenso vazio", "empobrecido e nu, como um arbusto que experimenta o primeiro inverno após uma floração ainda sem frutos." (MUSIL, 2003, p. 10). Logo a seguir ele faz amizade com dois colegas mais velhos, Reiting e Beineberg, "talentosos e de boas famílias, embora selvagens e violentos." (MUSIL, 2003, p. 13). Reiting apresenta características de um tirano, que exerce a vontade de poder como propõe Nietzsche, autor bastante conhecido de Musil. Especialmente maldoso, nada o divertia mais do que "atiçar pessoas umas contra as outras, submeter umas com a ajuda das outras, alimentando-se dos agrados e das adulações forçados que extraia delas, por trás dos quais sentia a resistência do ódio de suas vítimas." (MUSIL, 2003, p. 43). Beineberg, por sua vez, era um intelectual mistificador, com influência da filosofia indiana, que embasa sua superioridade no misticismo e na defesa de sacrifício que purifica o cosmos. Basini, um outro jovem que vai integrar o cenário da crise, é apresentado com fraca capacidade intelectual, inferioridade moral, porque mentia por vaidade, mas "possuía um agradável, envolvente encanto." ( MUSIL, 2003, p. 55). O círculo de violência tem início quando descobrem que Basini rouba dinheiro do armário de Reiting. Reiting e Beineberg resolvem puni-lo e humilhá-lo na pretensão de educar, corrigir sua falha moral. Como só esses colegas sabiam do roubo, eles aproveitam para explorar a vítima, que teme ser denunciada à direção da escola. Passam a protagonizar cenas de violência e exploração sexual, que logo atingem a perversão, pois Basini está totalmente subjugado. "Podemos fazer com ele", diz Reiting, "o que bem entendermos" (MUSIL, 2003, p. 52). Basini, por ser mais fraco e ter característica efeminada, torna-se alvo fácil para a mistura ambígua de desejo homossexual e crueldade e submete-se à chantagem. Enquanto isso, Törless deixa-se influenciar pelos amigos e passa a vivenciar uma ambiguidade de sentimentos diante das cenas de violência e abuso que presencia e, de certo modo, participa, no quarto vermelho, onde se encontravam às escondidas. Sente um desamparo íntimo que não lhe permitia encontrar o caminho de si mesmo. Dotado de extrema sensibilidade e de sutilezas intelectuais, interessase pelo infinito e pelo enigma entre números racionais e números imaginários ${ }^{8}$

\footnotetext{
8 A questão dos números imaginários reflete a preocupação constante de Musil com o abismo entre o racional e o irracional. Na resenha intitulada On the Edge of Revelation, Coetzee afirma a respeito do significado que a matemática assume em Musil: "No centro de seu pensamento está
} 
que não operam com a mesma ordem lógica, e isso encontra ressonância no seu anseio íntimo pelo misterioso e pela unidade.

A escola não consegue imprimir a força espiritual que precisaria, e nenhuma das leituras, nem dos clássicos, "nada exerceu verdadeira influência em sua personalidade." (MUSIL, 2003, p. 14). Mas havia tentativa de encontrar um caminho. Quando as aulas de matemática o interessaram, pensou: "Se isso que estão dizendo aí for realmente preparação para a vida, deve-se referir a alguma das coisas que estou procurando." (MUSIL, 2009, p. 81). Contudo, não obteve êxito na tentativa de levar adiante o enfrentamento intelectual de seus problemas, pois a conversa com o professor de matemática não foi produtiva. Ele alegou que o jovem aluno precisaria de mais uns 10 anos para compreender os números imaginários. E também o desestimulou a ler o livro de Kant que Törless havia avistado sobre a mesa, despertando-lhe certo interesse. A esse respeito, o narrador faz a seguinte observação:

Essa relação distorcida com literatura e filosofia surtiu sobre o futuro desenvolvimento de Törless um efeito pernicioso, que lhe proporcionaria muitas horas tristes. Pois desviava sua ambição de seus verdadeiros objetivos e, privado deles, procurara outros, caindo sob a influência de colegas, rapazes decididos e brutais. (MUSIL, 2003, p. 87).

Ao mesmo tempo em que ele percebe, sobretudo pelo choque do roubo, que os princípios morais são frágeis, seus colegas não têm dúvidas e põem em funcionamento uma ordem hierárquica baseada na força física e intelectual, na intriga e na chantagem, com vistas a realizar a punição. O

a ideia expressa sucintamente na metáfora matemática usada por Törless (não devemos esquecer que Musil é engenheiro de formação). Existe uma infinidade de números racionais, ou seja, números que podem ser escritos como a razão de dois números inteiros. Há também uma infinidade de números irracionais, números que não podem ser expressos como qualquer razão desse tipo. Mas as duas ordens de infinito não são comparáveis. A infinidade de irracionais é "maior" do que a infinidade de racionais. Em particular, entre quaisquer dois racionais, não importa o quão próximo estejam, encontra-se um conjunto de irracionais. Caminhando de um racional para o próximo, como fazemos todos os dias, é, na figura de Törless, como atravessar uma ponte cujos pilares são acompanhados por algo que não existe "realmente". Para viver e funcionar no mundo do racional, devemos banir deliberadamente de nossa consciência o irracional que está denso sob nossos pés e sobre nós. Devemos aceitar uma convenção sobre o que deve ser tratado como pertencente ao mundo real. Tal convenção irá definir a linguagem do cotidiano." 
pretendido castigo que querem impor a Basini é uma espécie de terrível farsa educacional e moral. Törless percebe a quebra da superficial respeitabilidade burguesa e "sentia-se de certa forma dilacerado entre dois mundos: um sólido e burguês, no qual tudo acontecia de modo sensato e regrado, como estava habituado em casa; outro aventuroso, sombrio, misterioso, sanguíneo, com surpresas inimagináveis." (MUSIL, 2003, p. 45). Diante disso, apresenta uma gama ampla de atitudes, ou confusões, que incluem desde uma aguda sensibilidade, certa conivência com o sadismo dos colegas que torturam Basini, busca de prazer erótico (sentia-se atraído pela beleza de Basini e chega a amá-lo) e de prazer intelectual até arrogância estética e estranhamento das experiências, pois muitas vezes permanece apenas como observador das cenas de violência conduzidas pelos colegas.

abuso físico e psicológico torna Basini totalmente objetificado, como ele mesmo confessa, numa conversa que teve com Törless: "Ele [Reiting] diz que, se não batesse em mim, teria de imaginar que eu sou um homem, e nesse caso não deveria ser tão carinhoso e terno comigo. Mas se bate em mim, eu não passo de um objeto, e ele não precisa se envergonhar." (MUSIL, 2003, p. 112 ). Törless irrita-se com a passividade de Basini em aceitar as agressões. Quando as torturas chegam ao limite do inaceitável, Törles aconselha Basini a se entregar ao Diretor da Escola. Esse ato não é motivado por um questionamento moral, mas por um objetivo egoísta de livrar-se da situação. A escola considera Basini culpado e o expulsa; Törless, ao ser chamado para depor sobre o caso, faz um discurso estranho, e a Direção sugere que seja educado em casa.

Oromance configura como se preparam as formas de autoritarismo. Cada vez mais a violência se amplia, apoiada num crescente desejo de poder sobre aquele que é considerado fraco, de modo totalmente indiferente a seu sofrimento. Adorno chamou isso de educação dos fortes, a educação pela força e pela disciplina, em que ser duro significa apenas "indiferença à dor. [...] A ideia de que a virilidade consiste num grau máximo da capacidade de suportar dor há muito se converteu em fachada de um masoquismo que - como mostrou a psicologia - se identifica com muita facilidade ao sadismo." (ADORNO, 1998, p. 682). Isso antecipa o ambiente cultural do nazismo, que acaba sendo profetizado por Reiting, ao afirmar: 
Aliás, gosto desses movimentos de massa. Ninguém faz nada de especial, e ainda assim as ondas se erguem cada vez mais alto, até se abaterem sobre as cabeças de todos. Vocês vão ver, ninguém se moverá e ainda assim haverá uma tempestade gigantesca. Para mim, será uma diversão extraordinária promover uma coisa dessas. (MUSIL, 2003, p. 128).

Esse ambiente de crise, de "homens cegamente enquadrados no coletivo, que convertem a si próprios em coisa, dissolvendo-se enquanto seres autodeterminados" (ADORNO, 1988, p. 683), é o que Musil antecipa por meio de seus personagens, especialmente em Basini, que se transforma em coisa diante do autoritarismo de Reiting, que facilmente chega à perversão. Sem saber, Musil descreve as estruturas da violência que sustentaram as ditaduras do século 20. Posteriormente, nos Diários do período de 1930-38, ele próprio reconhece com clareza que:

Muito tempo antes dos ditadores, nossa época já havia gerado seu culto espiritual. Vê-se o caso de George. E também de Kraus e Freud, Adler e Jung. Recorde-se também de Klages e Heidegger. $\bigcirc$ comum aqui é a necessidade de domínio e liderança, de uma espécie de salvação. Existem também traços comuns a todos os líderes? Por exemplo, valores firmes e fórmulas sob os quais se mantém e que podem, contudo, ser entendidos de modos totalmente diferentes. (MUSIL, 2009, p. 495).

Ou seja, os ditadores dependem também do fomento das tendências estéticas, da promoção de certos valores, do ambiente educacional. Como observa Rosenfield (2012b), Musil conhece os perigos de um mero esteticismo, que se recolhe no individualismo e facilmente se entrelaça com o reacionarismo político:

esteta, que perde o desafio intelectual de seus obscuros sentimentos e desejos, que falha em elaborar, passo a passo, o trabalho interno das emoções intensas que facilmente nos levam para outra direção, é o mais vulnerável de tipos sociais - vulnerável, particularmente às pressões, ameaças e sedução de poder tirano (do tipo Reiting) e à encenação 
teatral do esoterismo ritualístico, que tende a recorrer a lendas da antiga sabedoria e a um anseio sentimental pela perfeição perdida de culturas passadas. (ROSENFIELD, 2012 b, p. 44-45).

O romance dimensiona o ético no estético sem recair no esteticismo porque é capaz de trabalhar a violência não em seu conteúdo, mas no processo interno dos sentimentos, provocando aquilo que é próprio da estética: "emoção extrema". E isso permite expor a fragilidade do processo formativo, já que as sutilezas intelectuais e a imaginação de Törless não encontram acolhimento no ambiente escolar, que se torna pobre diante de seus anseios, que exigiriam "altos padrões de elaboração sentimental [...] Pelo contrário, a escola, como seus pais, oferece-lhe apenas um moralismo sentimental caseiro; enquanto seus colegas mais velhos oferecem uma brutalidade desenfreada, física e mental." (ROSENFIELD, 2012b, p. 43).

As dificuldades de Törless em integrar as experiências emocionais com o pensamento racional, e a ausência do confronto entre sentimentos e pensamentos o levam facilmente às confusões:

Sabia que perseguia algo indefinido, num caminho que conduzia ao seu mais remoto interior; e isso o deixava exausto. Habituara-se a esperar por descobertas extraordinárias, coisas ainda secretas, e fora assim que chegara aos estreitos e tortuosos aposentos da sensualidade. Não por perversão, mas devido à sua momentânea desorientação psicológica. (MUSIL, 2003, p. 127).

Ou seja, não se estabeleceu aquilo que Musil descreve nos Diários como sendo a formação: "um crescimento que, ao mesmo tempo, potência a plenitude do pensar, do sentir e do querer." (MUSIL, 2009, p. 24l, grifo do autor). Apesar de procurar algo mais sólido para a moral, ao final do romance, Törless é descrito como um esteta, de acordo com o ambiente cultural de fin de siècle, que busca refúgio no isolamento:

Posteriormente, passados os problemas de juventude, Törless veio a se tornar um homem de espírito refinado e sen- 
sível. Era uma dessas naturezas de esteta e de intelectual que sentem paz observando as leis e seguindo em certa medida a moral da sociedade, pois isso as exime de terem de refletir sobre as coisas grosseiras que ficam muito abaixo das sutis emoções espirituais. Só que a postura correta, um pouco irônica, de tais pessoas assume uma entediada indiferença sempre que exigimos que se interessem pelos temas morais. (MUSIL, 2003, p. 124).

Apesar de Musil colocar Törless num refúgio estético, não deixa de incluir a crítica sobre o mal-estar que o esteticismo provoca. $\bigcirc$ rumo que Törless assume está vinculado ao contexto de fin de siècle - em que o esteticismo se torna indiferente às correções morais (MUSIL, 2003, p. 124). Isso evidentemente não é apresentado como um modelo, mas é contraposto pelo narrador, que alerta sobre os efeitos perniciosos para o jovem que não conseguiu elaborar o desafio intelectual pelo trabalho interno de suas emoções e sentimentos, tornando-se mais vulnerável à influência maléfica dos colegas.

A crua exposição da violência no romance não pretendia ser um manifesto contra a educação ou as relações sociais, de acordo com a interpretação de Rosenfield (2012a, p. 81), mas se deve a um mal-estar mais primário daquele suposto por Freud, ou seja, deve-se a uma deficiência da elaboração imaginária, que dificulta um posicionamento ético. $\bigcirc$ romance não apresenta uma utopia, mas aponta para aquilo que Waldenfels (2007) descreve em suas pesquisas, apoiadas na fenomenologia: a violência não tem uma essência própria. Ela é cultural e historicamente variável, de acordo com um sistema de ordem e de regulação em que se estabelece. Atravessa vários domínios da vida, impressiona como algo intransponível, insolúvel, extraordinário que questiona toda a ordem, algo que não tem lugar próprio (WALDENFELS, 2007, p. 88-102). Sua existência está associada à violação que afeta alguém - no caso do romance é a violação contra Basini, mas também Törless se sente afetado por ela, só que de forma simbólica, embora nem sempre consiga ter uma atitude enérgica diante dos fatos que o levem a um posicionamento mais claro. Tampouco a violência pode ser compreendida como uma mera oposição entre "violência não racional e razão não violenta" (WALDENFELS, 2007, p. 102), porque elas se misturam. Com frequência ela é racionalizada e tende a ser ideologicamente carregada ou velada. Waldenfels 
(2007, p. 99) adverte que "moralistas que querem fazer a situação da violência menos ambígua do que ela é por separar estritamente luz e sombra, bem e mal, não somente falsificam o que está acontecendo, mas também prejudicam as vítimas."

○ romance não apresenta o mundo conciliado nem uma formação plena e harmônica como se desenvolve no clássico romance de formação, ao contrário, levanta questões no melhor estilo de Musil, que busca elucidar criticamente os descaminhos da cultura e da formação cultural. Justamente por acreditar que o ético está no estético, Musil oferece imagens simbólicas para promover o pensamento. A ação moral se entranha de tal maneira com a criação artística que não se enquadra em respostas esperadas pela normalização moral, mas expõe toda a complexidade da violência. $\bigcirc$ autor mostra com impiedosa lucidez as pequenas circunstâncias que, em geral, passam despercebidas e que preparam o nexo entre educação, mentalidade autoritária e violência.

Desse modo, a força poética do romance recria nossa leitura sobre educação e violência, mostrando que se continuarmos mutilados pela cultura, pela falta de compreensão da violência, não teremos categorias conceituais nem sensibilidade para compreender o que acontece conosco. Hoje há formas variadas de violência na sociedade e na educação brasileira que renovam a pergunta se podemos superar a barbárie ou se isso é uma ilusão. Contudo, obras de alto valor estético enriquecem nossa experiência cultural e constituem uma forma de autocompreensão moral e de conhecimento do mundo.

\section{REFERÊNCIAS}

ADORNO, T. Erziehung nach Auschwitz. In: ADORNO, T. (Org.). Gesammelte Schriften. Herausgegeben von Rolf Tiedemann. Darmstadt: Wissenschaftliche Buchgesellschaft, 1998. v. 10-2.

BOHRER, K. H. O ético no estético. In: ROSENFIELD, D. (Org.). Ética e estética. Rio de Janeiro: Zahar, 2001. p. 9-10.

COETZEE, J. M. On the Edge of Revelation. Disponível em: < http://www. robertmusil.net/musil/essays/J.M.\%20COETZEE\%20\%200n\%20the\%20 Edge\%20of\%20Revelation.pdf>. Acesso em: 18 maio 2017. 
EAGLETON, T. A ideologia da estética. Rio de Janeiro: Jorge Zahar Editor, 1993.

GADAMER, H.-G. Ästhetik und Poetik I. In: GADAMER, H.-G. Gesammelte Werke. Tübingen: Mohr Siebeck, 1999. v. 8. p. 232-239.

FOUCAULT, M. Tecnologías del yo. Tradução Mercedes Allendesalazar. Barcelona: Buenos Aires: México: Paidós, 1990.

FRÜCHTEL, J. Äthetische Erfahrung und moralische Urteil. Frankfurt am Main: Suhrkamp, 1996.

GOETHE, W. Os anos de aprendizagem de Wilhelm Meister. Tradução Nicolino Simone Neto. São Paulo: Editora 34, 2006.

HOFFMANN, G.; HORNUNG, A. Ethics and aesthetics: the moral turn of postmodernism. Heidelberg: Universitätverlag C. Winter, 1996.

LYOTARD, J.-F. Moralidades pós-modernas. Tradução Marina Appenzeller. Campinas: Papirus, 1996.

MASS, W. P. M. D. O cânone mínimo: o Bildungsroman na história da literatura. São Paulo: Editora UNESP, 2000.

MUSIL, R. O jovem Törless. Tradução Lya Luft. Rio de Janeiro: Globo; São Paulo: Folha de São Paulo, 2003.

MUSIL, R. Diários. Tradução Elisa Piqueras. Barcelona: Debolsillo, 2009.

NUSSBAUM, M. C. La terapia del deseo: teoría y práctica en la ética helenística. Barcelona: Paidós, 2003.

NUSSBAUM, M. C. Love's Knowledge: Essays on philosophy and literature. Oxford: Oxford University Press, 1992.

RORTY, R. Contingencia, ironía y solidaridad. Tradução Alfredo Eduardo Sinnot. Barcelona: Paidós, 1991.

ROSENFIELD, K. H. Freud e Musil - ou - psicanalista contra vontade. Pandaemonium Germanicum, São Paulo, v. 15, n. 20, p. 78-1 17, dez. 2012a. Disponível em: <http://periodicos.usp.br/pg/article/view/53627>. Acesso em: 03 maio 2017. 
ROSENFIELD, K. H. Musil's idea of poetic mastership and responsibility or: Törless as his first attempt to become a serious writer. Pandaemonium Germanicum, São Paulo, v. 15, i. 19, p. 17-48, July 2012b. Disponível em: <http://periodicos.usp.br/pg/article/view/39795>. Acesso em: 02 maio 2017.

SCHILLER, F. Cartas sobre a educação estética da humanidade. Tradução Roberto Schwarz. São Paulo: E.P.U., 1991.

STEINER, G. The Unfinished: Robert Musil. The New Yorker, April 17, 1995. Disponível em: <http://www.robertmusil.net/musil/essays/The\%20Unfinished. pdf $>$. Acesso em: 18 maio 2017.

THIHER, A. Understanding Robert Musil. Columbia: University South of Carolina Press, 2009.

VIEJA, M. T. L. Ética y literatura. Madrid: Editorial Tecnos, 2003.

WALDENFELS, B. The question of the other. New York: State University of New York Press, 2007.

WELSCH, W. Ästhet/hik: Ethische Implikationen und Konsequenzen der Ästhetik. In: WULF, C.; KAMPER, D.; GUMBRECHT, H. U. Ethik der Äthetik. Berlin: Akademie Verlag, 1994. p. 3-22.

WELSCH, W. (Hrsg.). Die Aktualität des Ästhetischen. München: Fink, 1993;

WELSCH, W. Estetização e estetização profunda ou: a respeito da atualidade do estético. Tradução Alvaro Valls. Porto Arte, Porto Alegre, v. 6, n. 9, p. 7-22, maio 1995.

WELSCH, W. Vernunft: Die zeitgenössische Vernunftkritik und das Konzept der transversalen Vernunft. Frankfurt am Main: Suhrkamp, 1996.

Recebido em:: 20 de novembro de 2017 Aceito em:: 11 de junho de 2018

Endereço para correspondência: Rua Teixeira de Carvalho, 219, 90880-300, Porto Alegre, Rio Grande do Sul, Brasil; nadjamhermann@gmail.com 